\title{
The Relationship Between Global Citizenship, Personality, and Social Dominance Orientation
}

\author{
Jonathan Appel ${ }^{1}$, Dohee Kim-Appel ${ }^{2}$, Alyse Dietz ${ }^{1}$, Alexis Glick ${ }^{1}$, Brianna Huether ${ }^{1}$, \\ Justin Kopronica ${ }^{1}$, Janae Walls ${ }^{1}$ \\ ${ }^{1}$ School of Criminal Justice \& Social Sciences, Tiffin University, Tiffin, U.S.A \\ ${ }^{2}$ Department of Counseling, Heidelberg University, Tiffin, U.S.A
}

Email address:

Appelj@tiffin.edu (J. Appel), dkimappe@heidelberg.edu (D. Kim-Appel)

To cite this article:

Jonathan Appel, Dohee Kim-Appel, Alyse Dietz, Alexis Glick, Brianna Huether, Justin Kopronica, Janae Walls. The Relationship Between Global Citizenship, Personality, and Social Dominance Orientation. International Journal of Education, Culture and Society.

Vol. 6, No. 4, 2021, pp. 153-158. doi: 10.11648/j.ijecs.20210604.18

Received: July 28, 2021; Accepted: August 19, 2021; Published: August 30, 2021

\begin{abstract}
The concept of global citizenship identity is a multidisciplinary construct that has been studied in recent years. Unfortunately, there is not much research, which has measured the impact of globalization on such psychological constructs as personality, identity, and social functioning. The purpose of the present research is to assess psychological and demographic variables that co-exist with a "Global Citizenship" measure. Global citizenship for this study is operationalized as the awareness and embracing of cultural diversity while promoting sustainability and social justice. Global citizenship includes a sense of responsibility to act. Theory and research suggest that being aware of one's connection with others in the world (global awareness) is rooted in settings that value global citizenship (normative environment) and can lead to greater identification with citizens worldwide. Specifically, the research presented is this paper consists of collecting and analyzing data, examining the interrelationships between global citizenship, a five-factor personality measure, demographic variables, a measure of social dominance, and a political orientation assessment. It was hypothesized personality variables would be able to predict level of global citizenship identity. Additionally, it was predicted Social Dominance Orientation (SDO) would be related to Global Citizenship Identity. The meaning and the implications of the findings obtained are discussed in the context of psychological, social and political behaviors.
\end{abstract}

Keywords: Global Citizenship, Five-Factor Model of Personality, Social Dominance, Political Psychology

\section{Background}

\subsection{Global Citizenship}

The concept of global citizenship identity is a multidisciplinary construct that has been re-examined in recent years [5, 7-9]. In the behavioral sciences, little research has empirically identified and measured the impact of globalization on identity, personality, and psychological functioning. Currently, there are also requests for assessment into the consequences of cultural [1] and global [3, 6] influences on social and psychological functioning. Global Citizenship focuses on the "wide lens" view of having a global perspective towards various issues pertinent to the psychology of identity, personality, and social behaviors [21].

\subsection{Five-Factor Model of Personality (BIG FIVE-OCEAN)}

From a personality viewpoint, many psychological characteristics can be placed into the "Big Five" traits. The Five-Factor Model (FFM) is an evidence-based multidimensional personality model that describes stability in emotions, cognition, and behavior as a function of five independent domains: Neuroticism, Extraversion, Openness to Experience, Agreeableness, and Conscientiousness [24].

These factors are described as follows [19];

(1) Extraversion; people high in extraversion are often talkative, enthusiastic, active, dominant, and sociable. Those scoring high have more interpersonal interactions with others than those scoring low. Extraverts also tend to develop relationships that are 
more social, are more likely to fall in love, and are more likely to experience pleasure.

(2) Agreeableness; Agreeableness is often expressed in how "likable" others may feel about a person. Individuals scoring high in agreeableness are seen as trusting, good-natured, and pleasant. Those low on this factor can be seen as suspicious, irritable, and contrary. Individuals who score high in agreeableness are not likely to engage in conflicts in interpersonal relationships. They are also less likely to be assertive when conflicts do occur.

(3) Neuroticism-Emotional Stability; this dimension refers to individuals that are often troubled by negative emotions such as insecurity and anxiety. Individuals high on the neuroticism sub-scale can be emotionally unstable, have excess distress, and are prone to low self-esteem. Individuals who score high on this dimension are less happy than low score individuals.

(4) Conscientiousness; this describes individuals who are ambitious, industrious, dependable, ambitious, responsible and persistent - individuals scoring high on this dimension value organization, are punctual, and are consistent. Individuals who score high in this dimension often do well academically, are well liked by their superiors and are loyal in relationships.

(5) Openness (to Experience); this dimension reflects being cultured, receptiveness to new ideas, places, and interests. Individuals who score high in openness are more likely to be curious, intelligent, intuitive, creative, and insightful.

\subsection{Social Dominance Orientation (SDO)}

According to researchers in this area-"social dominance orientation (SDO") is one's degree of inclination for desiring an inequality among social groups. Research in social dominance theory has demonstrated that (1) men are more social dominance-oriented than women; (2) high-SDO people seek hierarchy-enhancing professional roles; and (3) SDO was related to several social and political ideologies that support group-based hierarchies that encourage unequal treatment of groups or meritocracy). High SDO individuals support policies positions that are hierarchal-- regardless of implications for intergroup relationships or conflict (civil rights, social programs, and even military conflict) [20].

\section{Procedure}

A verbal explanation of the study petitioned participants. If one was interested, they were given a consent sheet that included a description of the purpose of the study and a statement of assurance of the confidentiality and anonymity of the data. If they agreed to be part of the study, they were then instructed to read and sign the informed consent form and were given a research packet containing questionnaires. The questionnaires in each packet contained: a Demographic Questionnaire (DQ), Global Citizen Scale, Ten-Item Personality Inventory, and Social Dominance Orientation (scale).
The Demographic Questionnaire (DQ) gathered the following information:

(1) Age

(2) Gender

(3) Race

(4) Country of Birth

(5) Current country of residence (and years of residency)

(6) Employment or School Status

(7) SES

(8) Political Orientation (continuum measurement)

(9) Political Party Identification (continuum measurement) Sample

The data in this study were obtained from 230 participants in the Midwest United States aged range from 18 to 62 years old. These individuals were from a non-clinical population, and they were solicited as volunteers. The mean age of the sample was 23.1 years, with a standard deviation of 9.26633. The ethnic background of this sample was primarily Caucasian (73\%), with African Americans (10\%) and (10\%) Middle East origin representing smaller proportions of the sample. The residence representation of the sample was the United States (100\%), with $11 \%$ of the sample being foreignborn. The most significant percentage of the sample $(45 \%)$ identified as "Middle Class"; with Upper Middle (17\%) and $36 \%$ as "Lower Middle Class". The gender representation of the sample was $58.7 \%$ female and $41.3 \%$ males.

This study examined through regression methods, whether assessments of the Five Factors Personality Models (OCEAN), political views, and social dominance beliefs would be able to predict Global Citizen Identity. Specifically it was hypothesized that:

(1) Hypothesis 1: Personality variables (five factor model) will predict Global Citizenship Identity.

(2) Hypothesis 2: Political Orientation will predict Global Citizenship Identity.

(3) Hypothesis 3: Social Dominance Orientation will predict Global Citizenship Identity.

(4) Additional, demographics patterns would be assessed for significant relationships.

\section{Results}

\subsection{Correlations of Variables}

A correlation matrix of all experimental variables were run. Beyond the significance associations mentioned in the regression models the following significant relationships were found:

Demographics

(1) GENDER (SEX) and GLOBAL CITIZENSHIP INVENTORY - Total Score (GCITotal) sig. correlated $\mathrm{r}=.308$ [.001] with Females more likely than males to have higher Global Citizenship Identity than Males.

(2) EMPLOYMENT/SCHOOL STATUS and GLOBAL CITIZENSHIP INVENTORY - Total Score (GCITotal) sig. correlated $\mathrm{r}=.452$ [.001] with more education associated to higher Global Citizenship Identity. 
(3) SOCIAL DOMINANCE ORIENTATION (SDO) and GENDER (SEX) sig. correlated $r=.-314$ [.001] with Males more likely than females scoring higher levels of SDO.

(4) SOCIAL DOMINANCE ORIENTATION (SDO) and SES sig. correlated $r=.282$ [.001] with higher SES being associated with higher levels of SDO.

(5) SOCIAL DOMINANCE ORIENTATION (SDO) and POLITICAL ORIENTATION-POLITICAL IDEOLOGY sig. correlated $r=.514$ [.001] with conservative orientation more likely associated with higher levels of SDO.

(6) SOCIAL DOMINANCE ORIENTATION (SDO) and POLITICAL PARTY sig. correlated $r=.506$ [.001] with a republican orientation more likely associated with higher levels of SDO.

(7) GLOBAL CITIZENSHIP INVENTORY-Total Score (GCITotal) SOCIAL DOMINANCE ORIENTATION (SDO) sig.neg correlated $\mathrm{r}=-.601$ [.001] with constructs highly inversely related (higher Global
Citizenship means lower SDO).

(8) POLITICAL ORIENTATION-POLITICAL IDEOLOGY sig. correlated $\mathrm{r}=.226[.001]$ with EMOSTAB with conservative orientation more likely associated with higher levels of Anxiety.

\subsection{Tests of Personality Dimensions' Prediction of Global Citizenship}

The first set of regression models were used to examine the basic relationship between measures of personality and a measure of Global Citizenship (GCTotal). It was tested whether Extroversion (EXTRAV), Agreeableness (AGREE), Consciousness (CONC), Emotional Stability (EMOSTAB) and Openness to Experience (OPEN) personality categories accounted for a significant amount of variance in predicting level of Global Citizenship. Overall the Big five in total was able to significantly predict Global Citizenship Identity. This affirms Hypothesis 1 (see tables 1 and 2).

Table 1. Model Summary.

\begin{tabular}{lllll}
\hline Model & R & R Square & Adjusted R Square & Std. Error of the Estimate \\
\hline 1 & $.508^{\mathrm{a}}$ & .258 & .241 & 21.73319 \\
\hline
\end{tabular}

a. Predictors: (Constant), OPEN, EMOSTAB, EXTRAV, AGREE, CONC.

Table 2. $A N O V A^{a}$.

\begin{tabular}{llllll}
\hline Model & & Sum of Squares & df & Mean Square & F \\
\hline \multirow{3}{*}{1} & Regression & 36736.133 & 5 & 7347.227 & 15.555 \\
& Residual & 105802.254 & 224 & 472.331 & \\
& Total & 142538.387 & 229 & & \\
\hline
\end{tabular}

a. Dependent Variable: GCTotal

b. Predictors: (Constant), OPEN, EMOSTAB, EXTRAV, AGREE, CONC.

Based on the resulting obtained regression statistics, it was found that three of the "Big Five" personality dimensions Agreeableness (AGREE), Consciousness (CONC), and Openness to Experience (OPEN) were the most robust in predicting the strength of Global Citizenship. The research hypotheses associated with these hypotheses were accepted. In other words, as measures of these personality dimensions increased in these participants, their global identity increased. These findings confirm a relationship between personality dimensions and having a Global Citizenship identity. This is to say that as an individual scored higher in agreeableness, consciousness, and open to experience they would likely to take and value global awareness with a greater identification with global citizens [15].

\subsection{Tests of Political Views and Prediction of Global Citizenship}

This set of regression models were used to examine the basic relationship between measures of political views and Global Citizenship Identity. It was tested whether Political Orientation-Political Ideology and Political Party Affiliation predicted a measure of Global Citizenship (GCTotal). It was found that Political Orientation-Political Ideology and Political Party Affiliation (together) predicted a measure of Global Citizenship (GCTotal) at .001 level. Thus, as one moves left of the political spectrum-Global Citizenship identity increases. This affirms Hypothesis 2 (see table 3).

Table 3. Model Summary.

\begin{tabular}{lllll}
\hline Model & R & R Square & Adjusted R Square & Std. Error of the Estimate \\
\hline 1 & $.595^{\text {a }}$ & .354 & .348 & 20.13806 \\
\hline
\end{tabular}

a. Predictors: (Constant), PARTY, POLIDEA.

\subsection{Tests of Social Dominance Prediction of Global Citizenship}

This study also explored whether level of Social
Dominance would predict a measure of Global Citizenship. Therefore, specific regression models were used to test whether the Social Dominance Orientation score (SDO) total score accounted for a significant amount of variance in 
predicting Global Citizenship total scores (GCTotal). It was found that variance in Social Dominance Orientation score (SDO) were significant (.001) predicting Global Citizenship total scores (GCTotal) in this sample. This affirms Hypothesis 3 (see tables 4 and 5).

Table 4. Coefficients ${ }^{a}$.

\begin{tabular}{lllllll}
\hline \multirow{2}{*}{ Model } & & \multicolumn{2}{l}{ Unstandardized Coefficients } & Standardized Coefficients & \multirow{2}{*}{ t } & \\
\cline { 3 - 6 } & & B & Std. Error & Beta & 45.805 & .000 \\
\multirow{2}{*}{1} & (Constant) & 142.008 & 3.100 & & -11.346 & .000 \\
\hline
\end{tabular}

a. Dependent Variable: GCTotal.

Table 5. Model Summary.

\begin{tabular}{lllll}
\hline Model & R & R Square & Adjusted R Square & Std. Error of the Estimate \\
\hline 1 & $.601^{\mathrm{a}}$ & .361 & .358 & 19.98931 \\
\hline
\end{tabular}

a. Predictors: (Constant), SDOTOTAL.

\section{Discussion-Conclusion}

This study highlights that the Five-Factor Model of Personality can be useful for understanding the dynamics inherent in a Global Citizenship Identity, indicating this may be a psychological trait that is shaped by the same factors associated in personality development. The "Openness to Experience" (OE) personality dimension appears to be the most robust personality and predictive factor related to a Global Identity (as predicted in Hypothesis 1). This dimension was also the most inversely related to a Social Dominance Orientation measure. As expected, a Social Dominance Orientation was also inversely related to a Global Citizenship Identity, as it was also related to a more conservative political orientation (as predicted in Hypothesis 2).

This study also confirmed prior psychological research that consistently found that political conservatives are more anxious than progressives, resulting in a desire for stability, structure and simplicity in the face of complexity $[11,2,4$, $12,17]$. This suggests views of social dominance may be as least in part related to desiring social order and hierarchy in the face of anxiety. Researchers note that the conditions under which the need for closure are likely to arise because of "the difficulty of information processing and its laboriousness" [15]. Evolutionary pressures have given us the biological systems that tread towards quick and intuitive decisions based on an autopilot system of thinking. This system of thinking and decision-making is more primitive and automatic and driven by fear and the flight or fight response. Nobel Prize-winning psychologist Daniel Kahneman notes there are two systems of thinking in our brains: System 1 and System 2. System 2 is the intentional system is deliberate and reflective. System 1, as mentioned, is the "fast" or more reflexive circuit. Kahneman terms these as "fast" and "slow" thinking [13]. He notes it takes time and processing effort to identify and override the bias expressed in System 1.

System 1 seeks the safety of certainty (even if in error or imagined) because, as a species, when we are faced with a potentially life-threatening situation, we must make an instant decision and act on it. There is no time for 'perhaps this' or 'perhaps that'. There is the inherent propensity of limbic and amygdala activation (fear and aggression) in our advanced brain functions, which often precedes the more recent frontal cortical (logic centers) emergence in human evolution. Psychology has shown that deep inherent (and unconscious) processes in System 1 thinking provides the tendency towards cultural and racial prejudice (implicit bias), even among the most "enlightened" among us $[16,10]$.

System 2 is more open to complexity and ambiguities to arrive at the truth of reality, but one must tolerate any anxiety this may cause. System 2 thinking requires deeper mental processing and tolerance of uncertainty and internal conflicts (dissonance) and can see facts over opinions. It can recognize and see things from multiple viewpoints and recognize selferror. It acknowledges things are not always what they seem or have absolute certitude. System 2 thinking can take in data and arrive at rational conclusions.

Are The Differences in Political Thinking is PersonalityBased

Interestingly, the need for certainty or cognitive closure is positively associated with social conservatism and negatively correlated with economic conservatism [18]. In other words, veering from social traditions and norms are seen (or felt) as dangerous to personal safety. This need for safety may not apply to seeking economic certainty. This may partly explain why social conservatives may vote against their own economic interests, as they are more driven by groupconstructed consensuses as traditional/ longstanding social values.

Psychological research has consistently found that political conservatives are more anxious than more progressives, which may result in a desire for stability, structure, and simplicity in the face of complexity and personality profile that is less "open to experience" (OE) [12, 2, 4, 15, 23]. "Conservatism helps to protect people against some of the natural difficulties of living," states social psychologist Paul Nail; "The fact is we do not live in a completely safe world. Things can and do go wrong. However, if I can impose this 
order on it by my worldview, I can keep my anxiety to a manageable level" [22]. Neuroscience has also found that biologically, social conservatives have a larger amygdala in the brain [14]. That is the part of the brain partly responsible for threat identification and fear-based reactions and some personality results found in the present study (low OE and increased emotional reactivity).

Scholars suggest that this type of research demonstrates the need for security and certainty — such as social conformity, intolerance of ambiguity, threat sensitivity, and needs for order, structure, and security - attract people to a more conservative ideology [11] as well as the before mentioned study variable of social dominance. One must also keep in mind - that if extreme political progressiveness is associated with less fear or anxiety, this does open the door for more permissiveness in risk-taking behaviors. This lack of protective anxiety can result in vulnerability in the acceptance or normalization of potentially dangerous behaviors. A given amount of fear or anxiety is required for safety or discrimination of actual peril.

\section{Further Research and Limitations}

Further research in the global citizenship area should increase the diversity of the sample.--This sample was a limited population drawn from the Midwest -samples drawn from an international location would strengthen the generalizability of the results. Social Desirability may have been a limitation. Implicit measurements towards social groups may have a more accurate view of attitudes.

\section{References}

[1] Adams, G., \& Markus, H. R. (2004). Toward a conception of culture suitable for a social psychology of culture. In $\mathrm{M}$. Schaller, \& C. S. Crandall (Eds.), The psychological foundations of culture (pp. 335-360). Mahwah, NJ: Lawrence Erlbaum Associates.

[2] Altemeyer, B. (1998). The other "authoritarian personality". In Advances in experimental social psychology (Vol. 30, pp. 47-92). Academic Press.

[3] Arnett, J. J. (2002). The psychology of globalization. American Psychologist, 57, 774-783.

[4] Chirumbolo, A. (2002). The relationship between need for cognitive closure and political orientation: The mediating role of authoritarianism. Personality and Individual Differences, 32 (4), 603-610.

[5] Davies, L. (2006). Global citizenship: Abstraction or framework for action? Educational Review, 58, 5-25.

[6] Delanty, G. (2000). Citizenship in a global age: Society, culture, politics. Buckingham, UK: Open University Press.

[7] Der-Karabetian, A. (1992). World-mindedness and the nuclear threat: A multinational study. Journal of Social Behavior and Personality, 7, 293-308.

[8] Dower, N. (2002a). Global citizenship: Yes or no? In N.
Dower, \& J. Williams (Eds.), Global citizenship: A critical introduction (pp. 30-40). New York, NY: Routledge.

[9] Dower, N. (2002b). Global ethics and global citizenship. In N. Dower, \& J. Williams (Eds.), Global citizenship: A critical introduction (pp. 146-157). New York, NY: Routledge.

[10] Greenwald, A. G., \& Krieger, L. H. (2006). Implicit bias: Scientific foundations. California law review, 94 (4), 945-967.

[11] Jost, J. T., Federico, C. M., \& Napier, J. L. (2013). Political ideologies and their social psychological functions. The Oxford handbook of political ideologies, 232-250.

[12] Jost, J. T., Napier, J. L., Thorisdottir, H., Gosling, S. D., Palfai, T. P., \& Ostafin, B. (2007). Are needs to manage uncertainty and threat associated with political conservatism or ideological extremity? Personality and social psychology bulletin, 33 (7), 989-1007.

[13] Kahneman D. (2011) Thinking, fast and slow. Farrar, Straus and Giroux, New York.

[14] Kanai, R., Feilden, T., Firth, C., \& Rees, G. (2011). Political orientations are correlated with brain structure in young adults. Current biology, 21 (8), 677-680.

[15] Kemmelmeier, M. (1997). Need for closure and political orientation among German university students. The Journal of Social Psychology, 137 (6), 787-789.

[16] Kruglanski, A. W., Pierro, A., Mannetti, L., \& De Grada, E. (2006). Groups as epistemic providers: need for closure and the unfolding of group-centrism. Psychological review, 113 (1), 84 .

[17] Madva, A., \& Brownstein, M. (2018). Stereotypes, prejudice, and the taxonomy of the implicit social mind1. Nôus, 52 (3), 611-644.

[18] Malka, A., Soto, C. J., Inzlicht, M., \& Lelkes, Y. (2014). Do needs for security and certainty predict cultural and economic conservatism? A cross-national analysis. Journal of personality and social psychology, 106 (6), 1031.

[19] McCrae, R. R., Zonderman, A. B., Costa Jr, P. T., Bond, M. H., \& Paunonen, S. V. (1996). Evaluating replicability of factors in the Revised NEO Personality Inventory: Confirmatory factor analysis versus Procrustes rotation. Journal of Personality and Social Psychology, 70 (3), 552.

[20] Pratto, F., Sidanius, J., Stallworth, L. M., \& Malle, B. F. (1994). Social dominance orientation: A personality variable predicting social and political attitudes. Journal of personality and social psychology, 67 (4), 741.

[21] Reysen, S., \& Katzarska-Miller, I. (2013). A model of global citizenship: Antecedents and outcomes. International Journal of Psychology, 48 (5), 858-870.

[22] Tatera, K. (2016, February 1). Neuroscience reveals the differences between Republican and Democrat brains. The Science Explorer. Accessed at: http://thescienceexplorer.com/humanity/neuroscience-revealsdifferences-between-republican-and-democrat-brains

[23] Webster, D. M., \& Kruglanski, A. W. (1994). Individual differences in need for cognitive closure. Journal of personality and social psychology, 67 (6), 1049.

[24] Wiggins, J. S. (Ed.). (1996). The five-factor model of personality: Theoretical perspectives. Guilford Press. 


\section{Biography}

Jonathan Appel has worked in the field of Behavioral Health for over two decades. He has worked with individuals, groups, families, and organizations as a counselor, psychotherapist, clinical supervisor, program director, consultant, and educator. Dr. Appel is currently a full professor of Psychology and Criminal Justice at Tiffin University.

Dohee Kim-Appel, Ph.D., LPCC-S, IMFT-S, LICDC, ATR-BC, NCC is an Associate professor in the Master of Arts in Counseling (MAC) at Heidelberg University. She has decades of experience in the field of behavioral health before she decided to teach, train and develop ethical counselors full time.

Alyse Dietz has a bachelor's degree in Criminal Justice with specialties in Forensic Psychology and Addictions Counseling from Tiffin University. She is currently pursuing a graduate degree in Psychology. She was a research member of the Psychology Club at Tiffin University.

Alexis Glick has a bachelor's degree in Psychology from Tiffin University with a specialty in Addictions Counseling. She was a research member of the Psychology Club at Tiffin University. She also works in the mental health field.

Brianna Huether has a bachelor's degree in Psychology from Tiffin University with specialties in Human Services and Addictions Counseling. She was a research member of the Psychology Club at Tiffin University. She also works in the mental health field.

Justin Kopronica has a bachelor's degree in Psychology from Tiffin University with a specialty in Human Services. He was a research member of the Psychology Club at Tiffin University.

Janae Walls has a bachelor's degree in Psychology from Tiffin University with specialties in Human Services and Addictions Counseling. She was a research member of the Psychology Club at Tiffin University. She currently is a graduate student. 